\section{Critérios de notificação e tendência temporal da epidemia de AIDS no Estado de São Paulo, 1980-98}

\author{
AIDS case-definitions and trends in \\ AIDS cases: S. Paulo, Brazil, 1980-98
}

\section{Resumo}

Os casos de AIDS diagnosticados entre 198098, em pessoas com 13 anos de idade e mais, foram notificados segundo diferentes critérios. O objetivo deste trabalho é estimar a tendência temporal da epidemia de AIDS por critério de notificação. A partir do Banco de Dados da Coordenação Nacional de DST/ AIDS, foi utilizada a contagem de linfócitos T CD4+ dos casos notificados pelos critérios CDC/Modificado, Rio/Caracas e "CD4" e a distribuição dos casos de AIDS de acordo com estes critérios hierarquizados entre as categorias de exposição. A mediana dos casos notificados para a contagem de linfócitos T CD4+, segundo os critérios CDC/Modificado, Rio/Caracas e "CD4" hierarquizados, é de respectivamente 86 células $/ \mathrm{mm}^{3}$, 135 células $/ \mathrm{mm}^{3} \mathrm{e} 215$ células $/ \mathrm{mm}^{3}$. De acordo com os critérios CDC/Modificado e Rio/ Caracas, observa-se uma queda significativa do número de novos casos de AIDS entre homossexuais e UDI, desde 1992, e entre heterossexuais masculinos e femininos, desde 1996. O critério "CD4" não deve ser utilizado na análise da tendência temporal da epidemia de AIDS entre 1980-98. A análise da tendência temporal da epidemia de AIDS, considerando-se o período assintomático da infecção pelo HIV, revela um decréscimo da infecção entre homossexuais e UDI já em 1985. A queda do número de novos casos de AIDS entre heterossexuais masculinos e femininos desde 1996 pode estar refletindo tanto os avanços da terapia anti-retroviral como as medidas de prevenção da população heterossexual a partir do momento em que a AIDS deixou de ser caracterizada como uma doença que atingia essencialmente homossexuais masculinos e UDI.

Palavras-chave: Síndrome de imunodeficiência adquirida/epidemiologia. Notificação de doenças. Saúde pública.

\section{Samuel Kilsztajn}

Laboratório de Economia Social do Programa de Estudos

Pós-Graduados em Economia Política - LES/PUCSP

R. Mq.Paranaguá 164/602

01303-050 São Paulo SP

skil@pucsp.br 


\section{Abstract}

Between 1980 and 1998, AIDS cases among people who are 13 years old or over in the State of Sao Paulo were reported by different AIDS-case definitions. The objective of this paper is to estimate the trend of reported AIDS cases according to the three main Brazilian AIDS-case definitions. Utilizing the database from the Brazilian National Coordination of STD/AIDS, the study used CD4 T-lymphocytes count of cases reported by CDC/Adapted, $\mathrm{PAHO} /$ Caracas/Rio and "CD4" criteria; and the distribution of cases of AIDS per exposure category according to these criteria. The medians for CD4 T-lymphocytes count according to the CDC/ Adapted, $\mathrm{PAHO} /$ Caracas/Rio and "CD4" criteria are respectively 86 cells $/ \mathrm{mm}^{3}, 135$ cells/ $\mathrm{mm}^{3}$ and 215 cells $/ \mathrm{mm}^{3}$. According to the CDC/Adapted and PAHO/Caracas/Rio criteria, the number of new AIDS cases among homosexuals and IDU has been decreasing since 1992 and among heterosexual men and women since 1996. The "CD4" criteria should not be utilized for analyzing the trend of AIDS between 1980 and 1988. The analysis of the trend of AIDS cases, considering the HIV clinical latency period without AIDS, reveals the decrease of new infections among homosexual men and IDU since 1985 . The reduction of new AIDS cases among heterosexual men and women from 1996 on can be reflecting both the anti-retroviral therapy in process and the prevention measures for heterosexuals since 1990, when AIDS stopped being considered a disease that affects essentially homosexuals and IDU.

Keywords: Acquired immunodeficiency syndrome/epidemiology. Disease notification. Public health

\section{Introdução}

Entre 1980 e 1998, os casos de AIDS, diagnosticados em pessoas com 13 anos de idade e mais, foram notificados segundo diferentes critérios.

Numa primeira fase, o critério de notificação CDC dos Estados Unidos foi sendo adaptado às condições diagnósticas laboratoriais e clínicas do Brasil sob a denominação de critério CDC/Modificado. Em 1992, a partir de experiências na cidade do Rio de Janeiro, foi introduzido o critério Rio/Caracas. Em 1998, com o objetivo de permitir a vigilância epidemiológica mais precoce da AIDS, foi introduzido o critério de notificação baseado na quantificação sérica de linfócitos T CD4+ (doravante chamado de "CD4") para pessoas com contagem de linfócitos T CD4+ inferior a 350 células $/ \mathrm{mm}^{3}$ (Ministério da Saúde ${ }^{1}$ 1998).

O "CD4" é um marcador de imunodeficiência e a evolução da doença está inversamente correlacionada aos valores do "CD4", isto é, quanto mais baixo o "CD4", maior a probabilidade do paciente com infecção pelo vírus HIV desenvolver manifestações clínicas da AIDS. Nos Estados Unidos, desde 1993, são notificadas pelo "CD4" as pessoas que apresentam contagem de linfócitos T CD4+ inferior a 200 células $/ \mathrm{mm}^{3}$ (Bartlett ${ }^{2}$ 2000).

Além dos três critérios acima mencionados, são ainda utilizados três critérios excepcionais de notificação: o critério Excepcional CDC; o critério Excepcional Óbito; e o critério Excepcional ARC + Óbito, definidos em 1995 ( Ministério da Saúde ${ }^{1}$ 1998).

Dada as alterações nos critérios utilizados para a definição dos casos de AIDS, o objetivo deste trabalho é estimar a tendência temporal da epidemia de AIDS por critério de notificação. Cabe lembrar que os três critérios excepcionais são excludentes, mas os critérios CDC/Modificado, Rio/Caracas e "CD4" não o são, isto é, podem gerar dupla contagem, não podendo, portanto, ser somados sem ajustes. 


\section{Método}

Para a análise da tendência temporal da epidemia de AIDS no Estado de São Paulo foram utilizados os casos notificados pelos critérios CDC/Modificado, Rio/Caracas e "CD4" do Banco de Dados da Coordenação Nacional de DST/AIDS (CN-DST/AIDS ${ }^{3}$ 2001).

A notificação dos casos de AIDS pelo Centro de Referência e Treinamento de DST/ AIDS do Estado de São Paulo, segundo os critérios excepcionais que utilizam os registros de óbitos da Fundação Sistema Estadual de Análise de Dados (SEADE), ainda encontra-se em fase de andamento, e não pode ser utilizada para a análise da tendência temporal da epidemia de AIDS no estado (1996 e 1998 já foram objeto de atualização, embora o ano de 1997 ainda não tenha sido atualizado). Além disto, embora excludentes por definição, foi constatada indevida sobreposição de casos notificados pelos critérios excepcionais entre si e com os critérios CDC/ Modificado, Rio/Caracas e "CD4".

Para hierarquizar os critérios CDC/Modificado, Rio/Caracas e "CD4", utilizandose o "CD4" menor que 200 células $/ \mathrm{mm}^{3}$ como padrão-ouro de definição de casos de AIDS, foram calculadas a sensibilidade (percentual de pacientes que satisfazem o padrão) e a especificidade (percentual de pacientes que não satisfazem o padrão) para os três critérios analisados a partir dos casos notificados de AIDS até 30 de dezembro de 2000. Os casos de AIDS foram, ainda, distribuídos de acordo com a contagem de linfócitos T CD4+, para cada um dos três critérios hierarquizados. Inúmeros casos diagnosticados a partir de 1996 registram a contagem de linfócitos T CD4+ provavelmente em decorrência de atraso da notificação*.

Os casos notificados de AIDS de acordo com os critérios hierarquizados foram distribuídos em quatro grupos por categoria de exposição hierarquizada: os dois primei- ros formados respectivamente por homossexuais (e bissexuais) masculinos e usuários de drogas injetáveis (UDI), que correspondem às principais categorias de exposição atingidas pela AIDS nos anos oitenta do século XX; e os dois seguintes compostos respectivamente por heterossexuais masculinos e femininos, que correspondem às principais categorias de exposição atingidas pela AIDS nos anos noventa do mesmo século**. As demais categorias de exposição, incluindo os casos com categoria ignorada, não constituíram objeto de estudo desta etapa da pesquisa.

A análise da tendência temporal da epidemia de AIDS até 30 de dezembro de 2000 no Estado de São Paulo restringe-se aos casos diagnosticados entre 1980 e 1998. Os anos mais recentes não foram utilizados para a análise devido ao atraso da notificação.

\section{Resultados}

Entre os 95376 casos de AIDS notificados até30 de dezembro de 2000 para pessoas com 13 anos de idade e mais, no Estado de São Paulo, 50173 casos foram notificados pelo critério CDC/Modificado, 62844 pelo critério Rio/Caracas, e 17186 pelo critério "CD4".

Dentre os 86726 casos notificados pelos critérios CDC/Modificado, Rio/Caracas e "CD4", o banco ${ }^{3}$ informa a contagem de linfócitos T CD4+ de 17677 casos de AIDS (93\% dos casos que apresentam contagem de linfócitos T CD4+ foram diagnosticados a partir de 1996).

A sensibilidade dos critérios CDC/Modificado, Rio/Caracas e "CD4", de acordo com o padrão-ouro "CD4" menor que 200 células $/ \mathrm{mm}^{3}$, é de respectivamente $36,2 \%, 46,6 \%$ e 100,0\% (dado que, pelo critério “CD4", são notificadas todas as pessoas HIV positivas com “CD4" menor que 350 células $/ \mathrm{mm}^{3}$ ); e a especificidade dos critérios de acordo com o mesmo padrão é de respectivamente $84,9 \%, 75,6 \%$ e $6,6 \%$ (Tabela 1 ).

* Para o atraso de notificação ver Barbosa, Struchiner 1997.

* Para o conceito de vulnerabilidade entre as categorias de exposição ver Mann ${ }^{5}$ 1993, cap. 11. 
Tabela 1 - Sensibilidade e especificidade dos critérios CDC/Modificado, Rio/Caracas e "CD4" de acordo com o padrão-ouro "CD4" menor que 200 células $/ \mathrm{mm}^{3}$.

Table 1 - Sensitivity and specificity of CDC/Adapted, Rio/Caracas and "CD4" criteria according to gold standard "CD4"less than 200 cells $/ \mathrm{mm}^{3}$.

\begin{tabular}{lrrrr}
\hline Critério & \multicolumn{2}{c}{ Sensibilidade } & \multicolumn{2}{c}{ Especificidade } \\
\cline { 2 - 5 } & casos & $\%$ & casos & $\%$ \\
\hline CDC/adaptado & 3693 & 36.2 & 6354 & 84.9 \\
Rio/Caracas & 4752 & 46.6 & 5658 & 75.6 \\
"CD4" & 10195 & 100.0 & 491 & 6.6 \\
Total & 10195 & - & 7482 & - \\
\hline
\end{tabular}

O critério CDC/Modificado, além de ser o primeiro critério de notificação utilizado para definir casos de AIDS no País, é o critério menos sensível e mais específico entre os três critérios analisados neste trabalho. Foram, portanto, considerados como Critério CDC/Modificado todos os casos notificados por este critério, mesmo aqueles que apresentam notificação simultânea entre os demais 5 critérios de notificação.

O critério Rio/Caracas foi o segundo critério adotado no País e, em termos de sensibilidade e especificidade, constitui o critério intermediário entre o $\mathrm{CDC} /$ Modificado e o "CD4". Todos os casos notificados pelo critério Rio/Caracas não notificados pelo critério CDC/Modificado, independentemente de serem notificados nos demais 4 critérios, foram, assim, denominados Rio/Caracas'.
Finalmente, todos os casos notificados pelo "CD4" não notificados pelos critérios CDC/Modificado e/ou Rio/Caracas, independentemente de serem notificados nos demais 3 critérios, foram denominados "CD4"."

Os ajustes realizados para evitar a dupla contagem dos casos notificados de AIDS resultaram em 50173 casos notificados pelo critério CDC/Modificado; 27103 pelo critério Rio/Caracas' (excluídos os 35741 casos notificados simultaneamente pelos critérios Rio/Caracas e CDC/Modificado) e 9450 pelo critério "CD4'” (excluídos os 7736 casos notificados simultaneamente pelos critérios "CD4" e CDC/Modificado e/ou Rio/Caracas). Os critérios CDC/Modificado, Rio/Caracas' e "CD4'" somam 86726 casos notificados (Tabela 2). Entre os demais 8650 casos,

Tabela 2 - Sensibilidade e especificidade dos critérios CDC/Modificado, Rio/Caracas e "CD4" de acordo com o padrãoouro "CD4" menor que 200 células $/ \mathrm{mm}^{3}$.

Table 2 - Sensitivity and specificity of CDC/Adapted, Rio/Caracas and "CD4" criteria according to gold standard "CD4"less than 200 cells $/ \mathrm{mm}^{3}$.

\begin{tabular}{|c|c|c|c|c|c|c|c|c|}
\hline \multirow{2}{*}{$\begin{array}{l}\text { Período de diagnóstico } \\
\text { e categorias }\end{array}$} & \multirow{2}{*}{$\begin{array}{c}\text { CDC } \\
\text { adaptado }\end{array}$} & \multirow{2}{*}{$\begin{array}{c}\text { Rio/ } \\
\text { Caracas* }\end{array}$} & \multicolumn{3}{|c|}{ "CD4" (células/mm³) } & \multirow[t]{2}{*}{ Subtotal } & \multirow[t]{2}{*}{ Outros } & \multirow[t]{2}{*}{ Tota } \\
\hline & & & $0-199$ & $200-349$ & Total & & & \\
\hline 1980-1998 & 45969 & 23893 & 2244 & 3105 & 5349 & 75111 & 8085 & 83196 \\
\hline Homossexual: homem & 13513 & 5806 & 568 & 759 & 1327 & 20646 & 1183 & 21829 \\
\hline UDI & 6472 & 3692 & 93 & 96 & 189 & 10353 & 896 & 11249 \\
\hline Heterossexual:homem & 10679 & 6209 & 598 & 749 & 1347 & 18235 & 469 & 18704 \\
\hline Heterossexual: mulher & 6877 & 3840 & 730 & 1245 & 1975 & 12692 & 328 & 13020 \\
\hline Subtotal & 37541 & 19547 & 1989 & 2849 & 4838 & 61926 & 2876 & 64802 \\
\hline Outros** & 8328 & 4346 & 255 & 256 & 511 & 13185 & 5209 & 18394 \\
\hline $1999-200$ & 4304 & 3210 & 2020 & 2081 & 4101 & 11615 & 565 & 12180 \\
\hline Total & 50173 & 27103 & 4264 & 5186 & 9450 & 86726 & 8650 & 95376 \\
\hline
\end{tabular}

Fonte: elaborado a partir de CN-DST/AIDS, 2001/Source: CN-DST/AIDS, 2001

* dupla contagem excluída/double counting excluded; ** 95\% categoria ignorada/95\% ignored categories 
5618 foram notificados pelos critérios excepcionais e 3032 casos não estão associados a nenhum dos 6 critérios de notificação.

Dentre os 17677 casos de AIDS com informação da contagem de linfócitos T CD4+, 4821 referem-se ao critério CDC/Modificado, 3406 ao Rio/Caracas' e ao 9450 “CD4'”. A Figura 1 apresenta a distribuição dos casos de AIDS por "CD4" notificados até 30 de dezembro de 2000 para pessoas com 13 anos de idade e mais no Estado de São Paulo segundo os critérios hierarquizados CDC/ Modificado, Rio/Caracas' e "CD4'". As medianas dos casos de AIDS por "CD4" para os critérios CDC/Modificado, Rio/Caracas' e "CD4"” são respectivamente 86 células $/ \mathrm{mm}^{3}$,
135 células $/ \mathrm{mm}^{3}$ e 215 células $/ \mathrm{mm}^{3}$. Cerca de dois terços dos casos notificados pelo critério CDC/Modificado apresentavam "CD4" menor que 150 células $/ \mathrm{mm}^{3}$ e cerca de dois terços dos casos notificados pelo critério Rio/Caracas' apresentavam "CD4” menor que 200 células $/ \mathrm{mm}^{3}$.

Dos 86726 casos notificados pelos critérios CDC/Modificado, Rio/Caracas' e "CD4'” no Estado de São Paulo até 30 de dezembro de 2000, 75111 casos foram diagnosticados entre 1980 e 1998. Os 75111 casos, de acordo com as categorias de exposição hierarquizadas, podem ser distribuídos entre 20646 homossexuais masculinos, 10353 UDI, 18235 heterossexuais masculinos, 12692 heteros-
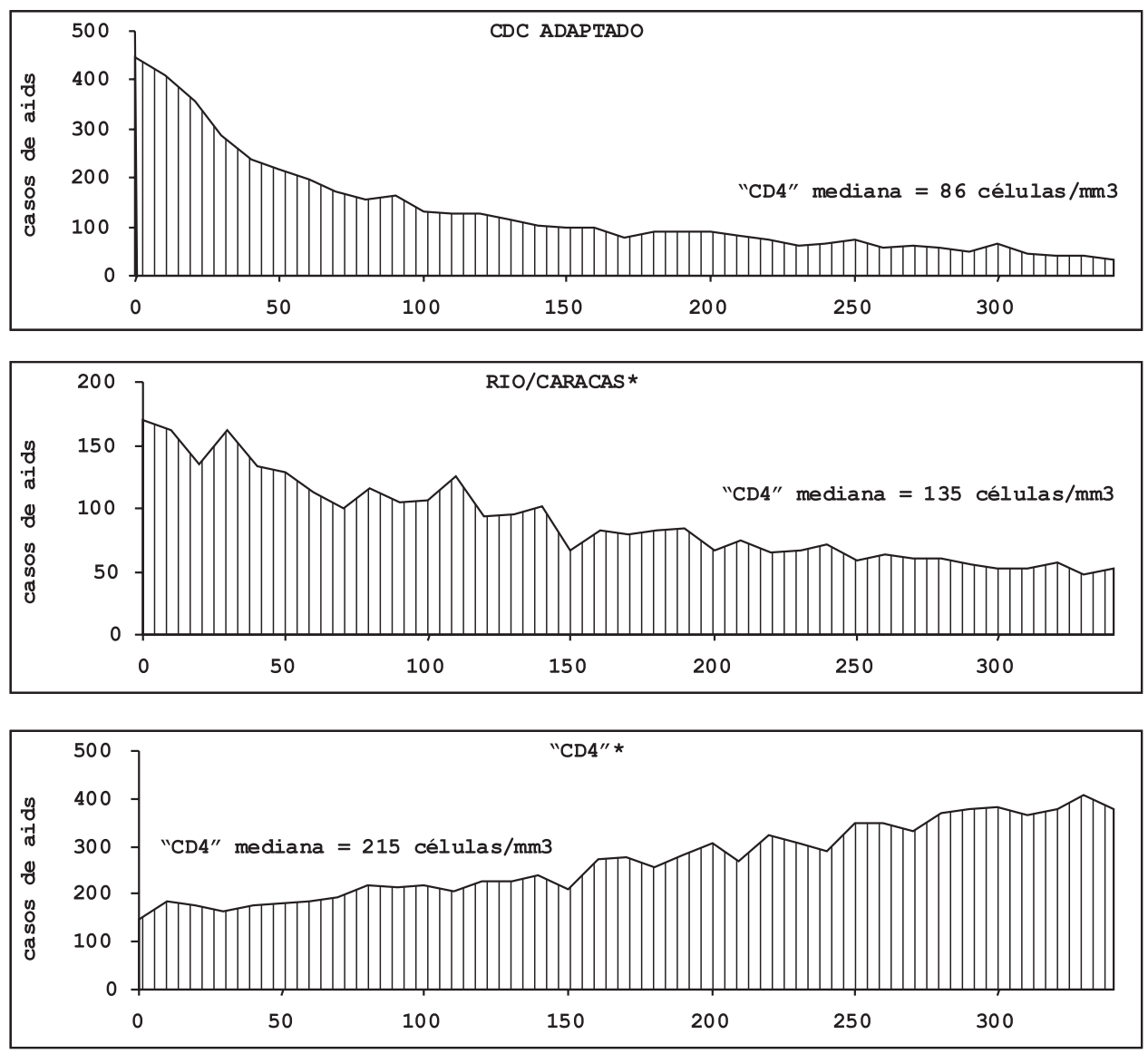

Fonte: elaborado a partir de CN-DST/AIDS, 2001/Source:CN-DST/AIDS, 2001

* dupla contagem excluída/double counting excluded

Figura 1 - Distribuição dos casos de AIDS por quantificação sérica de linfócitos T CD4 segundo critérios de notificação (13 anos e mais) Estado de São Paulo.

Figure 1 - AIDS cases distribution by CD4 T-lymphocytes count according to AIDS case definition (13 and more years old) State of Sao Paulo. 
sexuais femininos e outros 13185 casos, dos quais $95 \%$ correspondem a casos com categoria de exposição ignorada (Tabela 2 ).

Os homossexuais e UDI, que foram as primeiras categorias atingidas pela AIDS, de acordo com o critério CDC/Modificado, apresentaram elevação do número absolu- to de novos casos até 1992 e decréscimo significativo até 1998. Em 1992 foram diagnosticados respectivamente 1604 e 824 novos casos entre homossexuais e UDI e, em 1998, 701 e 219 novos casos (Figura 2).

De acordo com o critério Rio/Caracas', os casos de AIDS entre homossexuais apre-
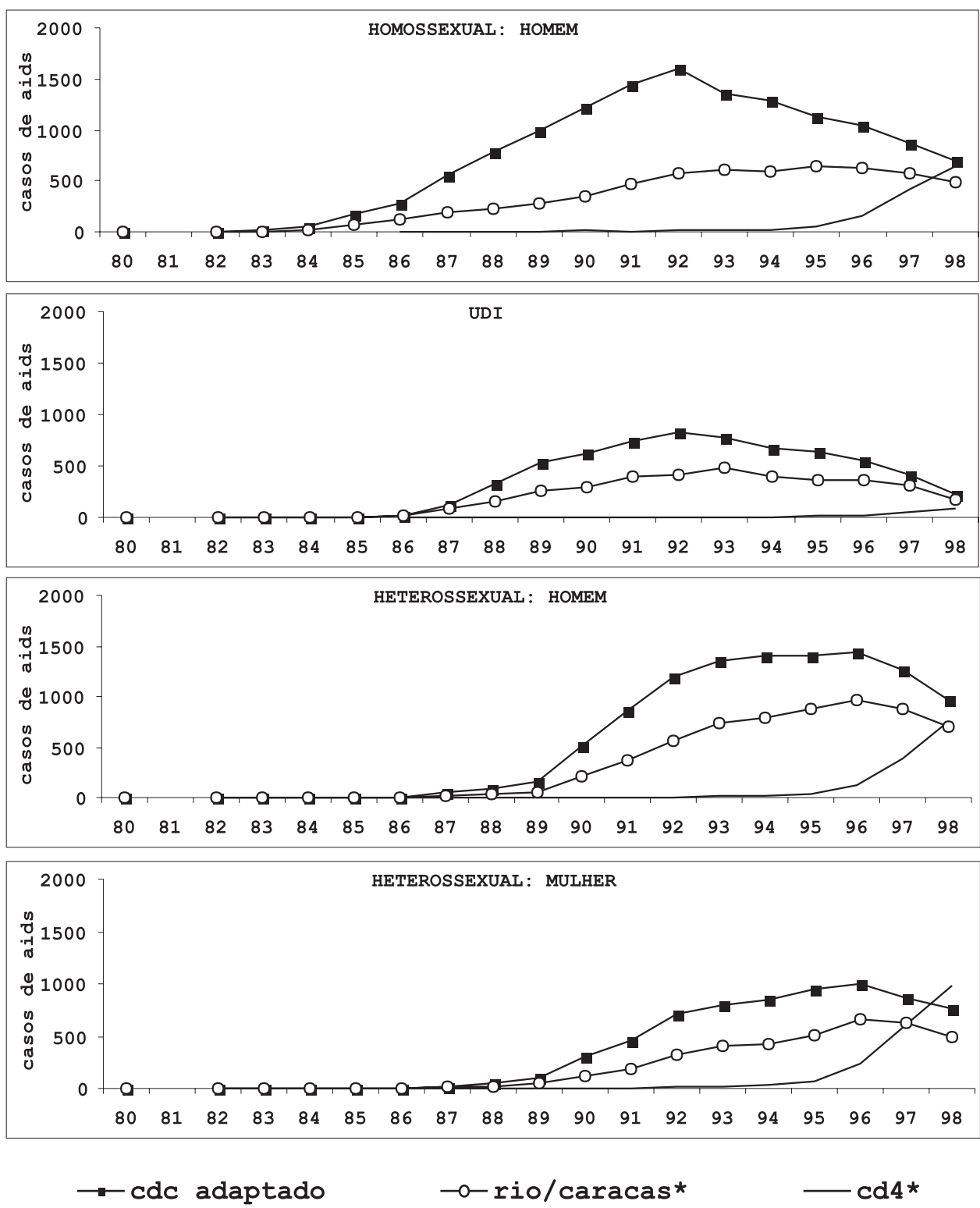

Fonte: elaborado a partir de CN-DST/AIDS, 2001/Source: CN-DST/AIDS, 2001

* dupla contagem excluída/double counting excluded

Figura 1 - Distribuição dos casos de AIDS por categoria de transmissão segundo critérios de notificação (13 anos e mais) Estado de São Paulo.

Figure 1 - AIDS cases distribution by category of transmission according to AIDS case definition (13 and more years old) State of Sao Paulo. 
sentam ligeira elevação de 581 casos em 1992 para 642 casos em 1995, seguida de queda, com 484 casos em 1998. Para os UDI a queda do número de novos casos segundo o critério Rio/Caracas' tem início em 1993.

Somente a partir de 1990 é que a AIDS começa a atingir a população heterossexual masculina e feminina de modo significativo, para atingir 1192 homens e 704 mulheres em 1992, segundo o critério CDC/Modificado. A taxa de crescimento é posteriormente reduzida e o número de novos casos entre heterossexuais atinge seu ponto máximo para homens e mulheres, tanto pelo critério CDC/Modificado como pelo critério Rio/ Caracas', em 1996 (Figura 2).

Somente em 1998 começam a ser notificados os casos de AIDS pelo critério "CD4", mais sensível que os dois critérios acima mencionados. Mas, devido ao atraso da notificação, foram notificados pelo critério "CD4" casos diagnosticados anteriormente a 1998. De acordo com o critério “CD4'”, o número de casos de AIDS passa de $187 \mathrm{em}$ 1995 para 2748 em 1998 para o total das categorias (que inclui os casos com categoria de exposição ignorada).

Deve-se considerar, ainda, que entre os 5349 casos de AIDS diagnosticados pelo critério “CD4'” entre 1980 e 1998, para todas as categorias, $55 \%$ apresentavam "CD4" maior ou igual a 200 células por $\mathrm{mm}^{3}$ de soro.

\section{Discussão}

OS dados apresentados na Tabela 2 e na Figura 1 confirmam que o critério CDC/ Modificado é mais específico e menos sensível que o critério Rio/Caracas que, por sua vez, é mais específico e menos sensível que o critério "CD4". Considerando-se que, sem tratamento, a contagem de linfócitos T CD4+ no sexto ano da infecção é de aproximadamente 350 células $/ \mathrm{mm}^{3}$, os sintomas constitucionais (incluídos na escala do critério Rio / Caracas) surgem no oitavo ano e as doenças oportunistas (características do critério CDC/Modificado) aparecem no nono ano da infecção (Bartlett ${ }^{2} 2000$ ), os casos notificados pelo critério Rio/Caracas, sem trata- mento, levariam cerca de 1 ano e os casos notificados pelo critério "CD4" levariam cerca de 3 anos para serem notificados pelo critério CDC/Modificado.

Isto significa que, com a introdução do critério Rio/Caracas em 1992, uma parte significativa da notificação de novos casos de AIDS era decorrente da introdução de um critério mais sensível. O mesmo fenômeno ocorreu com a introdução do critério "CD4" menor que 350 células $/ \mathrm{mm}^{3}$, em 1998 . Considere-se ainda que, dado o atraso da notificação, este fenômeno tem reflexos na notificação dos casos diagnosticados nos anos imediatamente anteriores à introdução dos novos critérios.

De acordo com a pesquisa realizada para mensurar a sensibilidade e a especificidade de quatro critérios de AIDS em 136 pacientes UDI com HIV em Barcelona ${ }^{6}$, o uso do critério Rio/Caracas implicou o aumento de 87\% no número de casos; e o uso do critério CDC norte-americano, revisado em 1993 (que amplia a definição de casos de AIDS para pessoas com infecção HIV e "CD4" < 200 células $/ \mathrm{mm}^{3}$ ), implicou o aumento de $171 \%$ no número de casos em relação ao critério CDC norte-americano de 1987.

A análise da tendência temporal da epidemia de AIDS pelo critério CDC/Modificado sugere que o número de novos casos de AIDS tenha sido reduzido a partir de 1992 para homossexuais masculinos e UDI. Para a população heterossexual masculina e feminina, depois do acentuado crescimento do número de casos entre 1990 e 1992, a taxa de crescimento de novos casos de AIDS foi reduzida e, após 1996, o número de casos passou a apresentar queda em termos absolutos.

De acordo com o critério CDC/Modificado, considerando-se a média de 8 anos assintomáticos entre a infecção pelo HIV e a manisfestação da AIDS (Bartlett² 2000), pode-se estimar que o número de infecções pelo HIV entre homossexuais e UDI foi reduzido em meados da década de oitenta. $\mathrm{O}$ ano de 1985, que assistiu à quadruplicação do número de novos casos e óbitos por AIDS, constitui o marco da disseminação da AIDS 
no Estado de São Paulo. A doença, em meados dos anos oitenta do século XX, atingia essencialmente homossexuais e UDI e a divulgação das projeções catastróficas do período devem ter sido suficientes para reduzir o número de infecções entre homossexuais e UDI, já em 1985. ${ }^{\text {-9 }}$

A queda do número de novos casos de AIDS entre heterossexuais masculinos e femininos, desde 1996, pode estar refletindo tanto os avanços da terapia anti-retroviral como as medidas de prevenção da população heterossexual, a partir do momento em que a AIDS deixou de ser caracterizada como uma doença que atingia, essencialmente, homossexuais masculinos e UDI.

Em relação aos avanços da terapia antiretroviral, o esquema múltiplo introduzido no final de 1996 pode estar retardando significativamente o aparecimento das doenças oportunistas que levariam à notificação da AIDS pelo critério CDC/Modificado (Dhalia et al. ${ }^{10} 1999$ ).

Por outro lado, a população heterossexual masculina e feminina só deve ter começado a adotar medidas preventivas no início dos anos noventa, quando descobriu que também era vulnerável à AIDS. Neste sentido, a queda do número de novos casos de AIDS entre heterossexuais masculinos e femininos pelo critério CDC/Modificado pode também estar refletindo a diminuição do número de infecções pelo HIV destas categorias de exposição, já no início dos anos noventa.

Ao ser introduzido o critério Rio/Caracas em 1992, eleva-se o número de casos notificados em decorrência da maior sensibilidade do novo critério em relação ao Critério CDC/Modificado até então utilizado. Os reflexos deste novo critério também atingem anos imediatamente anteriores a 1992, devido ao atraso da notificação. O crescimento do número de casos diagnosticados pelo critério Rio/Caracas' até 1992 não reflete o crescimento do número de novos casos, mas essencialmente $\mathrm{o}$ atraso da notificação.

Entre 1992 e 1995, o critério Rio/Caracas, por ser mais sensível, acaba por anteci- par o número de novos casos que, considerando-se a evolução natural da doença, só preencheriam o critério CDC/Modificado no espaço de aproximadamente um ano. Isto explica não só o aumento do número de casos de AIDS pelo critério Rio/Caracas, como a forte desaceleração do número de novos casos de AIDS na população homossexual e UDI pelo critério CDC/Modificado, entre 1992 e 1995. Somados os critérios CDC/Modificado e Rio/Caracas, o número de novos casos de AIDS entre 1992 e 1995 reduz-se de 2185 para 1770 casos entre homossexuais, e de 1233 para 992 casos entre UDI.

O mesmo raciocínio pode ser utilizado na análise da tendência temporal da epidemia entre heterossexuais masculinos e femininos. Em 1992, o critério Rio/Caracas antecipa a notificação de casos que seriam notificados pelo Critério CDC/Modificado no espaço de aproximadamente um ano. Em 1996, diminuem tanto o número de novos casos entre heterossexuais masculinos como o número de novos casos entre heterossexuais femininos, tanto pelo critério CDC/ Modificado quanto pelo critério Rio/Caracas. Mais uma vez, esta queda no número de novos casos pode estar refletindo tanto os avanços da terapia anti-retroviral como a queda do número de infecções pelo HIV no início dos anos noventa.

Com a introdução do critério "CD4", foram notificados 2748 novos casos de AIDS, diagnosticados em 1998, que não seriam notificados pelos critérios menos sensíveis CDC/Modificado e Rio/Caracas. Destes 2748 casos, $56 \%$ foram notificados com "CD4" maior ou igual a 200 células $/ \mathrm{mm}^{3}$. Deve-se considerar que o critério "CD4" com a contagem de linfócitos T CD4+ menor que 350 células $/ \mathrm{mm}^{3}$ foi introduzido no País com o objetivo de permitir a vigilância epidemiológica mais precoce da AIDS, e que nos Estados Unidos só são notificadas pelo "CD4" as pessoas com contagem de linfócitos T CD4+ inferior a 200 células $/ \mathrm{mm}^{3}$ (Bartlett ${ }^{2} 2000$ ).

Assim, como foi ressaltado na análise do critério Rio/Caracas, o crescimento do número de casos diagnosticados pelo critério "CD4" até 1998 não reflete o crescimento do 
número de novos casos, mas essencialmente o atraso da notificação. Neste sentido, para o estudo da tendência temporal da epidemia de AIDS entre 1980 e 1998, o critério "CD4" não pode ser somado aos critérios CDC/Modificado e Rio/Caracas. Os critérios excepcionais também não podem ser incluídos no estudo da tendência temporal da epidemia de AIDS, entre 1980 e 1998, porque ainda encontram-se em fase de notificação.

Com este trabalho, pode-se concluir que o número de infecções pelo HIV entre homossexuais masculinos e UDI apresenta-se em queda, desde meados dos anos oitenta, período da disseminação da AIDS no Estado de São Paulo, com efeito sobre a notificação da AIDS nestas categorias de exposição, desde 1992.
A queda do número de novos casos de AIDS entre heterossexuais masculinos e femininos, desde 1996, pode estar refletindo tanto os avanços da terapia anti-retroviral como as medidas de prevenção da população heterossexual, a partir do momento em que a AIDS deixou de ser caracterizada como uma doença que atingia essencialmente homossexuais masculinos e UDI.

\section{Agradecimentos}

Anacláudia Rossbach (PUCSP), Marcelo Bozzini da Camara (PUCSP), Manuela Santos Nunes do Carmo (PUCSP), Marcos Cleuton (CN-DST/AIDS) e Rosa de Alencar Souza (CRT-DST/AIDS-SP), pela colaboração, e aos pareceristas da Revista Brasileira de Epidemiologia, pelas sugestões.

\section{Referências}

1. Ministério da Saúde. Revisão da definição nacional de casos de AIDS em indivíduos com 13 anos ou mais, para fins de vigilância epidemiológica. Brasília (DF); 1998.

2. Bartlett JG. Medical care of patients with HIV infection. Philadelphia: LWW; 2000.

3. Ministério da Saúde. Coordenação Nacional DST/AIDS - CN-DST/AIDS. Banco de dados de AIDS (atualizado para 30 de dezembro de 2000). Brasília(DF); 2001.

4. Barbosa MTS, Strushiner CJ. Estimativas do número de casos de AIDS: comparação de métodos que corrigem o atraso da notificação. In: Ministério da Saúde. $A$ epidemia da AIDS no Brasil: situação e tendências. Brasília (DF); 1997.

5. Mann J et al., organizadores. A AIDS no mundo. Rio de Janeiro: ABIA; 1993.
6. Miranda PSC, Andrés M, Caylá JA, Galdós-Tangüis H, García de Olalla P. Validation of four AIDS-case definitions in HIV-infected intravenous drug users in Barcelona, Spain. Rev Bras Epidemiol 1999; 1:170-6.

7. Buchalla CM. AIDS: o surgimento e a evolução da doença. In: Monteiro CA, organizador. Velhos e novos males da saúde no Brasil. São Paulo: Hucitec; 1995.

8. Parker $\mathrm{R}$ et al., organizadores. A AIDS no Brasil. Rio de Janeiro: ABIA; 1994

9. Ministério da Saúde. A epidemia da AIDS no Brasil: situação e tendências. Brasília (DF); 1997.

10. Dhalia C, Barreira D, Castilho EA. A AIDS no Brasil: situação atual e tendências. Bol Epidemiol AIDS 1999:13(1). 